\title{
A reforma administrativa
}

\section{e a capacidade estatal no Brasil e na Venezuela em análise comparada*}

\author{
Administrative reform \\ and state capacity in Brazil and Venezuela
}

\author{
Marcos Sepúlveda**
}

RESUMO: 0 presente artigo visa revisar como ocorreram as reformas administrativas no Brasil e na Venezuela. Nesse aspecto, questiona-se: quais são as semelhanças e diferenças da administração pública e como pode ser vista a capacidade estatal de ambos países? A hipótese inicial é que possível haver uma separação entre três períodos históricos, tendo o grau de institucionalidade, participação, além da probidade ao patrimônio público como um dos norteadores para esta mensuração. Para tanto, optou-se por referenciais teóricos nacionais, que estavam inseridos na reforma administrativa no Brasil, assim como venezuelanos relacionados ao tema.

PalavraS-Chave: Administração Pública; Capacidade Estatal; Reforma Administrativa; Brasil; Venezuela.

ABSTRACT: This article aims to review how administrative reforms took place in Brazil and Venezuela. In this regard, the question is: what are the similarities and differences of public administration and how can the state capacity of both countries be seen? The initial hypothesis is that it is possible to have a separation between three historical periods, with the degree of institutionality, participation, in addition to the probity of public assets as one of the guidelines for this measurement. For that, we opted for national theoretical references, which were inserted in the administrative reform in Brazil, as well as Venezuelans related to the theme.

KEYWORDS: Public administration; State capacity; Administrative reform; Brazil; Venezuela.

Recibido: 27 de noviembre de 2019

Aceptado: 12 de agosto de 2020

Lectura y revisión lingüística: Dra. Marisela Colín Rodea. Escuela Nacional de Lenguas, Lingüística y Traducción, UNAM.

** Universidade Federal Fluminense, Brasil (marcosaraujoba@gmail.com). 
INTRODUÇÃO

$\mathrm{P}$

assadas mais de duas décadas que ocorreram as reformas administrativas, Brasil e Venezuela se distanciam economicamente, socialmente, mas como se pode analisar essa diferença em repaíses? Como cada administração pública se desenvolveu ao longo do tempo e quais foram as principais etapas que caracterizam esses processos históricos?

O objetivo desse artigo é analisar como a administração pública e a capacidade estatal se desenvolveram ao longo do tempo no Brasil e na Venezuela. Diante disso, questiona-se quais são as semelhanças entre as duas burocracias, assim como as diferenças.

Em primeiro momento, será exposta a evolução da administração pública em ambos os países. Nesse sentido, afere-se as possibilidades de separação histórica. Assim, é possível dividi-las em três períodos históricos, incluindo as ampliações estatais decorrente das reformas administrativas.

Diante disso, serão analisados os modelos de desenvolvimento e os alicerces da administração pública no século Xx, para que seja possível analisar como sucedeu-se no século xxI. Para tanto, propõe-se uma análise institucional sobre as normais legais de cada país.

Num segundo momento, revisa-se sobre a eficácia das respectivas normas, como também da própria administração pública -a institucionalidade, a reforma administrativa e os processos desenvolvidos-, com finalidade de haver maior congruência no desenvolvimento da política pública; como esta insere-se na esfera pública -a implementação e os resultados, desdobrando-se sobre a capacidade estatal.

Por fim, será apresentada uma conclusão que condensará os argumentos e fatos expostos supra de modo que se possa auferir como ambas as burocracias progrediram ao longo do tempo, em especial durante o século XXI. 


\section{A REFORMA ADMINISTRATIVA}

Embora próximos geograficamente, com fronteira que percorre os Estados de Roraima e Amazonas (Brasil) e Bolívar e Amazonas (Venezuela), esses países experimentaram processos burocráticos e administrativos distintos. Nesse sentido, é possível destacar três períodos essenciais tanto para o processo brasileiro quanto ao processo venezuelano.

No caso brasileiro, como bem destaca Bresser Pereira (1998), o processo é divido nas seguintes etapas: (I) nos anos 30 durante o governo Getúlio Vargas por meio da Constituição de 1937, que previu no art. 67 a criação de um departamento administrativo, associado a exigência de concurso público, já prevista na Constituição de 34. Esse passo, segundo Bresser Pereira (1998) foi o surgimento da profissionalização da burocracia no Brasil. Para Wahrlich (1974) é o principal destaque da primeira reforma administrativa.

Nesse caso, a criação em 1938 do Departamento Administrativo do Serviço Público (DASP) dará maior substância ao longo dos anos ao combate, embora ínfimo, da patronagem, assim como a impulsão de maior profissionalização. Para Wahrlich (1974), a reforma administrativa ao longo da década de 30 e 40 do século xx é caracterizada por visar os meios, a eficiência, a racionalidade dos processos administrativos sob ótica teórica de Weber, Taylor e Fayol. Assim, recorda-se que essa reforma foi inspirada nos conceitos de burocracia de Weber, que prevê como características e previsibilidade no funcionamento 0

1. Caráter legal das normas; 2. Caráter formal das comunicações; 3. Divisão do trabalho; 4. Impessoalidade no relacionamento; 5 . Hierarquização da autoridade; 6 . Rotinas e procedimentos; 7. Competência técnica e meritocracia; 8. Especialização da Administração; 9. Profissionalização dos participantes (Chiavenato 2014: 25).

Assim sendo, segundo Wahrlich (1974) foca-se na administração de pessoal, material, orçamento -incorporando nesse sentido o plano administrativo-, reestruturação administrativa e metodológica. No entanto, constatada a rigidez desse modelo de administração pública, ocorreu o 
segundo momento de reforma administrativa durante o período militar, sendo parte desta advinha da malograda tentativa reformista de Vargas na década de cinquenta perpassando pela criação da Comissão de Estudos e Projetos Administrativos (CEPA) durante o período de Juscelino Kubitschek; e no governo João Goulart, quando foi criado o cargo de Ministro Extraordinário para a Reforma Administrativa. No entanto, constata-se ao final do período civil que as minirreformas administrativas auxiliaram mais a eficiência e eficácia do Fisco, como também a criação do Serviço de Processamento de Dados (SERPRO).

Para Bresser Pereira (1998), essa segunda reforma, o qual trata como reforma parcial, é caracterizada como reforma desenvolvimentista. Se naqueles anos que o crescimento da economia de forma rápida era uma meta insaciável a ser alcançada pelos militares, por outro lado a administração pública encontrava-se muitas vezes em regras inflexível que culminavam na lentidão dos processos administrativos, até porque sob

[...] la perspectiva weberiana sobre la capacidad estatal sostiene que la capacidad de proveer bienes y servicios depende de que la burocracia sea una entidad corporativa coherente y los individuos estén aislado de las demandas sociales (Chudnovsky 2015: 22).

Assim, os militares buscaram superá-la parcialmente com a edição do Decreto-Lei no 200, o qual almejou uma administração pública flexível, além de estabelecer explicitamente cinco princípios fundamentais da reforma (planejamento, descentralização, delegação de competência, coordenação e controle). Nesse elastério, não havia maiores obstáculos legislativos como no passado, enfatizou-se a carreira, assim como os cargos. Outrossim, nesse momento a administração é norteada sob a ótica da concepção sistemática, da seletividade na execução e delegação, conforme aponta Wahrlich (1974). Também foi responsável por distinguir

[...] com clareza a administração direta da administração indireta, e garantiu às autarquias e as fundações desse segundo setor, e também às empresas estatais, uma autonomia de gestão muito maior do que possuíam anteriormente (Bresser Pereira 1998: 167). 
Fruto dessa reforma, segundo Wahrlich (1974), é o primeiro caso do modelo institution building, por considerar diversos aspectos como meio ambiente, organização administrativa, características intra e interorganizacional —o Departamento Nacional de Estradas de Rodagem (DNER). No entanto, os militares não se preocuparam com a necessidade da impessoalidade na gestão dos cargos públicos, a fim de haver maior restrição ao patrimonialismo na administração pública, embora houvesse demanda participativa da população e norma constitucional que o exigia, assim cargos efetivos tornou mais a exceção do que a regra, segundo Bresser Pereira (1998). Mas, esta digressão dos militares repercutirá na Constituição de 88 sob outras formas.

Nesse sentido, o Constituinte de 88 aperfeiçoa as exigências constitucionais surgidas in nuce em 1934, conforme o dispositivo do artigo 37 , inciso II, da CF de 88:

II - a investidura em cargo ou emprego público depende de aprovação prévia em concurso público de provas ou de provas e títulos, de acordo com a natureza e a complexidade do cargo ou emprego, na forma prevista em lei, ressalvadas as nomeações para cargo em comissão declarado em lei de livre nomeação e exoneração;

Diante disso, buscou-se a profissionalização dos cargos públicos, maior estabilidade ao servidor público para que se pudesse desenvolver e ater-se as políticas públicas de Estado, conforme mandamento constitucional. Dessa maneira, repeliu-se o direcionamento para formas clientelistas ou de grupo político que porventura pudesse estar em exercício, caso fosse somente cargos ad nutum:

[... o o grande mérito da Constituição de 1988 foi ter tornado obrigatório o concurso público, para a admissão de todo e qualquer funcionário. Esse foi, sem dúvida, um grande avanço, na medida em que dificultou o empreguismo (Bresser Pereira 2006b: 253).

No entanto, a administração pública solapou nos anos noventa novamente, pois ainda persistirá mandamentos ultrapassados, burocráticos e centralizados que foram preliminarmente afastados pelos militares, mas 
retomados pelos políticos, em especial PMDB e PFL, ao dar gestão fisiológica da res publica (Bresser Pereira 1998). Daí decorre um dos motivos para a terceira reforma administrativa brasileira.

Por fim, esse período é denominado como reforma gerencial. Nesta reforma foca-se em três aspectos fundamentais: I) a institucional II) cultural e III) gestão (Bresser Pereira 1998). Ater-se-á a primeira e última característica. Desse modo, um dos objetivos foi dar maior efetividade na prestação de serviço público, atendimento de qualidade para o cidadão, como de instrumento de valor, tendo em conta as práticas adotadas pela iniciativa privada, mas destacando a "esfera pública vista como local de aprendizagem social" (Abrucio 2006: 191). Outrossim, impulsiona-se a participação popular na gestão pública através dos orçamentos participativos que serão adotados pelas prefeituras, ainda pendente na esfera Federal (Sousa Santos e Avritzer 2002). Disso decorre, o que assevera Przeworski:

Há bons motivos para supor que a qualidade da intervenção do Estado na economia depende da organização interna do Estado - em particular das relações entre políticos e burocracia- e do desenho das instituições democráticas que determinam se os cidadãos podem ou não controlar os políticos (Przeworski 2006: 52).

Nessa linha, a estabilidade ao servidor público, por exemplo, é contestada visto que:

O Estado garante estabilidade aos servidores porque assim assegura maior autonomia ou independência à sua atividade pública, ao exercício do poder de Estado de que estão investidos; não a garante para atender a uma necessidade extremada de segurança pessoal, muito menos para inviabilizar a cobrança de trabalho, ou justificar a perpetuação de situações de excesso de quadro (Bresser Pereira 1998: 210).

Se o Brasil vivenciou esses três períodos, quais seriam os da Venezuela? É essencial pensar na alteração da matriz e do processo decisório venezuelano e destacar suas semelhanças e diferenças com o caso brasileiro, pois assim considerará 
[...] uma variedade extrema de elementos desigualmente pertinentes em cada caso concreto. A criação de uma nova instituição político-administrativa e/ou a modificação de uma legislação e/ou a transformação das destinações orçamentárias próprias a um subsistema dado da ação pública, necessitam considerar ao mesmo tempo a evolução e a configuração das interações entre atores públicos e privados, a influência dos fatores institucionais (no sentido mais tradicional), os modos de mobilização dos estrangeiros envolvidos, o impacto de matrizes cognitivas e normativas concorrentes, ou ainda o peso de dinâmicas propriamente políticas. Pensar a mudança significa pois, no fundo, estudar a ação do Estado de uma maneira diferente em relação às abordagens tradicionais da análise das políticas públicas (Muller e Surel 2002: 146).

Segundo Córdova Jaimes (2006), é possível elencar três fases da administração pública que culminaram em reformas estatais naquele país: I) modelo de administração burocrática-populista centralizado 1958-1989; II) modelo descentralizado do Estado 1990-1998; III) modelo burocrático-populista com base militar de 1999 até, pelo menos, o presente momento no qual este trabalho foi escrito (2019).

Na primeira fase, o Estado venezuelano possui crescimento burocrático, entendendo-se a estrutura organizacional, de cargos, além da criação de diversas empresas que participam ativamente da economia; centralização; discurso populista; a caracterização de divisão do poder entre dois principais partidos: Acción Democrática e COPEI (Córdova Jaimes 2006). Nesse elastério, esse período inicia em 1958, quando é celebrado o Pacto de Punto Fijo, momento que a Venezuela retorna à democracia e se estende até meados da década de oitenta. Para Brewer-Carías (1975), apesar de ter havido mudanças na estrutura do Estado na década de trinta, decorrente da inserção econômica do petróleo, somente na década de cinquenta o país torna-se mais urbano e há retorno do due process of law e, pode se considerar a primeira reforma administrativa. Ainda de acordo com Brewer-Carías (1975), enquanto na década de trinta havia apenas dois institutos autônomos, na década de setenta a administração pública venezuelana já se fazia presente em diversos setores tanto do direito público quanto do privado.

Contudo, esse período é caracterizado pela repartição dos cargos públicos entre os partidos políticos majoritários, perfazendo as práticas 
combalidas no ordenamento brasileiro, ainda que infimamente. Esse sistema é definido por Rey (1989) como sistema populista conciliação, já por Stambouli (2005) como compromisso entre forças heterógenas. De toda as formas, a reforma administrativa durante o Pacto visou articular o planejamento econômico e social com o administrativo almejando o desenvolvimento estrutural do país, dando tanto enfoque macro - o sistema administrativo do Estado - quanto micro, neste o estudo peculiar de cada departamental estatal. Assim, se o Brasil, criou o DASP, a Venezuela teve a Comissão de Administração Pública com atribuições similares ao caso brasileiro (Brewer-Carías 1975).

Para Coppedge (1994), embora esse modelo desenvolvimento tenha dado coesão e estabilidade à administração e aos mandatórios durante o Pacto de Punto Fijo, por outro lado provocou, aos poucos, o distanciamento entre sociedade e governo, inclusive da participação popular, já que os cargos públicos eram ocupados, em regra, em virtude da indicação dos partidos políticos no poder, ainda que Brewer-Carías (1975) mencione a regionalização e descentralização do Estado venezuelano logo após o fim do período militar, essas características desaparecem na década de oitenta. De todos os modos, Brewer-Carías (1975) admite o atraso administrativo venezuelano em comparação ao brasileiro.

No Brasil, há de desenvolvimento constitucional, inclusive na Constituição de 67 (art. 95) e 69 (art. 97) do período militar, que assegurava a participação popular na administração pública, através da ocupação de cargos de carreira: concurso público. Na Venezuela, os concursos públicos estão normatizados no art. 146 da Constituição de 99, tendo como um dos predecessores a Lei de Carreira Administrativa em 1970, como lembra Brewer-Carías (1975).

Dessa maneira, se por um lado a administração venezuelana foi capaz inicialmente de criar meios de comunicação com seus cidadãos, visto que eleições diretas ocorrem desde 1958, no Brasil só será vivenciada a partir de 1985, quando será eleito o governo civil de forma indireta, tendo em vista a limitação do governo dos militares desde 1964.

Por outro lado, nota-se uma dicotomia, enquanto os militares brasileiros visavam a descentralização, dando maiores poderes aos gestores da 
administração indireta, através da edição no Decreto-Lei n ${ }^{0}$ 200, a política venezuelana se desenvolveu visando a centralização do governo, dando maior ênfase nos poderes do governo nacional e nas competências do Presidente da República, ainda que tenha cedidas algumas aos órgãos e às instituições visando atendimento de demanda partidárias (Córdova Jaimes 2006).

Entretanto, não reluz a preocupação dos militares brasileiros com políticas equitativas ou discursos que tenham aproximação social, o que mais uma vez desassemelha o desenvolvimento administrativo de ambos os países nesse período. Durante esse período na Venezuela, os cidadãos acostumaram-se com a renda assimétrica advinda do petróleo, que perfazia inúmeros subsídios inefetivos, como salienta Coppedge (2002), o que resultava em "(...) um sistema econômico-social fundamentalmente orientado para o consumo e o desperdício e no qual a renda é muito concentrada e provavelmente tende a se concentrar de forma permanente" (Furtado 2008: 121).

Essa época abundância durará até a década de 80, quando o Presidente Luis Herrera Campins (1979-1984) desvaloriza a moeda frente ao dólar e, por consequência, reduz o poder de compra da população, já que o país importa grande parte dos produtos consumidos. Além disso, haverá aumento da inflação, dívida externa, sendo esses dois fatores comuns na América Latina à época (Vilda De Juan 1999; Naím 2001; López Maya 2016a).

Associado a isso, anos mais tarde, o protesto popular conhecido como "Caracaço", que tem origem na rejeição da população ao aumento do preço da gasolina, afetando diversos serviços, como o aumento da tarifa de transporte público, clarifica o agravamento da situação em decorrência do pacote econômico "El Gran Viraje" de Carlos Andrés Pérez, expondo a desconexão entre burocracia e cidadania (Magdaleno 2012).

Desses eventos surgirá a descentralização do poder nacional para os demais entes federados. Com isso, a população poderá eleger por via direta os prefeitos e governadores, dando também maior participação popular na política do país (Urbaneja 2009; Millán 2016). Ademais, em decorrência das 
medidas Consenso de Washington, as quais a adoção era conditio sine qua non para aceder aos recursos internacionais, Brasil e Venezuela se assemelham no modelo administrativo a partir do início da década de noventa.

Assim, ambos os modelos - do Brasil e da Venezuela - sucumbem nos anos noventa. No caso brasileiro, por ter sido incapaz e abandonado em 1985. Já no caso venezuelano, especialmente, por ter sido ineficiente às novas demandas do mundo que se globalizava e diante das perspectivas de novos dos modelos econômicos e políticos, além do desejo dos cidadãos por maior participação na administração pública do país, o qual também se insere as demandas dos brasileiros. Ademais, ambos Estados ao se expandirem, não acompanharam a prestação dos serviços públicos de forma eficiente, eficaz e efetiva para a população, o que colocava em xeque a legitimidade estatal (Bresser Pereira 2017).

Nesse sentido, o Brasil e a Venezuela executarão uma reforma gerencial, (neo)liberal. É importante constar que ambos os países ingressaram nos anos 90s com a necessidade de realizar ajuste fiscal, reformular e readequar as instituições as novas demandas dos cidadãos. Sobre gerencialismo entende-se, as lições de Souza que passa a eficiência ser o principal objetivo da política pública.

A partir da influência do que se convencionou chamar de "novo gerencialismo público" e da política fiscal restritiva de gasto, adotada por vários governos, novos formatos foram introduzidos nas políticas públicas, todos voltados para a busca de eficiência. Assim, a eficiência passou a ser vista como o principal objetivo de qualquer política pública, aliada à importância do fator credibilidade e à delegação das políticas públicas para instituições com "independência" política (Souza 2006:34).

Portanto, a descentralização é vista em ambos como conditio sine qua non, além de inserir os Estados apenas em áreas consideráveis vitais e necessárias para o desenvolvimento do país, mas visando o Estado Social. A privatização é adotada; criação de novas formas jurídicas, na Venezuela, os serviços autônomos; já no Brasil de Organizações Sociais; são exemplos de inovação jurídica que repercutirá em ambos os países ao tentar se aproximar dos demos e almejar um serviço mais eficiente e eficaz. 
É nesse período que mais se assemelham os referidos países. Porém, acaba-se ao final dos anos noventa, quando então o Hugo Chávez é eleito Presidente da República em 1998, pois conforme será visto adiante, a reforma administrativa é abandonada, dando origem ao modelo popular-burocrático de base militar, seguindo a terminologia adotada por Córdova Jaimes (2006).

Nesse elastério, o federalismo é mitigado dando mais ênfase nas políticas centrais do governo federal, ainda que no discurso e na Constituição de 99 estejam postos a descentralização como paradigma para o desenvolvimento das políticas públicas. Inclusive o próprio sistema político é alterado com a assunção de Chávez, dando origem à nova Constituição, umas das promessas de campanha de Chávez em 1998.

Para Rivas Leone (2008), há personalismo, aliado a instabilidade institucional, que produz políticas públicas conflitantes, como a questão

Quadro 1. Sistema político da Venezuela (1958-2005)

\begin{tabular}{|c|c|}
\hline Sistema de partidos 1958-1988 & Sistema de partidos 1993-2005 \\
\hline Baixa instabilidade eleitoral & Alta instabilidade eleitoral \\
\hline Alta identificação partidária & Baixa identificação partidária \\
\hline Partidária & Partidária \\
\hline $\begin{array}{l}\text { Inclusão, articulação e representação de } \\
\text { interesses gerais }\end{array}$ & $\begin{array}{l}\text { Inclusão, articulação e representação de } \\
\text { interesses particulares }\end{array}$ \\
\hline Partidocracia & Baixo partidarismo \\
\hline Participação & Abstencionismo \\
\hline Politização & Despolitização \\
\hline Partidário & Personalismo \\
\hline Reconhecimento constitucional (1961) & Não reconhecimento constitucional (1999) \\
\hline Liderança institucional & Liderança pessoal (caudilho) \\
\hline Estabilidade-centralização & $\begin{array}{l}\text { Instabilidade-descentralização-recentrali- } \\
\text { zação } \\
\end{array}$ \\
\hline Sistema de partidos institucionalizado & Sistema de partidos desinstitucionalizado \\
\hline Bipartidarismo estável & Multipartidarismo instável \\
\hline Liderança e atores tradicionais & Novas lideranças e atores emergentes \\
\hline Menor concorrência inter e intrapartidário & Maior concorrência inter e intrapartidário \\
\hline
\end{tabular}

Fonte: Rivas Leone, 2008:116 (tradução livre). 
dos Conselhos Comunais, os quais embora possam ser visto a prima facie como política pública de descentralização, na verdade, é extensão da centralização do governo central, já os Conselhos estão sob as ordens do Ministério do Executivo Nacional, dependendo dos recursos empenhados por este, como esclarece Addor (2015). No mesmo sentido, a criação da figura "protetores" de determinados Estados, municípios, reduzindo assim a independência regional ou local, já que esses são nomeados pelo governo central e possui atribuições similares aos candidatos opositores eleitos, sendo considerado uma forma de esvaziar federalismo e a autonomia dos entes (Aguiar 2012; López Maya 2016b).

Nesse período, enquanto a administração pública brasileira foi sucedânea de aprimoramento, seja no processo de administração pública, na forma gestão e na institucionalidade, na Venezuela houve não somente uma paralisia, mas uma reversão desta, para isso é necessário elencar alguns pontos importantes que desassemelham ambas as burocracias no século XXI.

Quadro 2. Reforma administrativa no Brasil e na Venezuela

\begin{tabular}{|l|l|}
\hline \multicolumn{1}{|c|}{ Brasil } & \multicolumn{1}{c|}{ Venezuela } \\
\hline 1. Burocrático (década de 30) & 1. Burocrático (década de 50) \\
\hline 2. Desenvolvimentista (década de 60) & 2. (Neo)Liberal (década de 90) \\
\hline 3. Gerencial-liberal (década de 90) & $\begin{array}{l}\text { 3. Burocrático centralizado com base militar } \\
\text { (a partir de 1999) }\end{array}$ \\
\hline
\end{tabular}

Fonte: Elaboração própria com base em Brewer-Carías (1975), Bresser Pereira (1998) e Córdova Jaimes (2006).

Para o lado brasileiro, é evidente que a reforma administrativa não parou no governo de Fernando Henrique Cardoso, o qual exerceu o poder legiferante por meio de normas infraconstitucionais e constitucionais (EC no 19/98). Por exemplo, Lei No 9.784/1999 que versa sobre o Processo Administrativo Federal; a Lei Complementar no 101/2000 que estabelece a responsabilidade fiscal; a Lei 10.520/2002, a qual institui a modalidade Pregão nas Licitações Públicas dando maior agilidade e eficiência na aquisição de bens e serviços comuns. 
Assim sendo, esta é seguida no governo Lula através da edição da Lei Complementar n⿳0 135/2010, conhecida como "Ficha Limpa" que dá maiores garantias aos administrados na escolha do governante, resguardando a res publica em consonância ao princípio da moralidade; o Decreto $\mathrm{n}^{\mathrm{O}}$ 5.378/2005 que institui o Programa Nacional de Gestão Pública e Desburocratização (GESPÚBLICA), o qual tem como um dos objetivos correlacionar os resultados das ações governamentais com a satisfação dos cidadãos. É também de fundamental importância a Lei de Acesso à Informação (Lei 12.527/2011) no período de Dilma Rousseff, em que estabelece o princípio da transparência ativa das informações públicas.

Nesse mesmo sentido, a Lei no 13.303/2016, já no governo Temer, que aprimora o estatuto jurídico das estatais, vedando, por exemplo, a participação daqueles que tenham sido filiados a partidos políticos nos últimos trinta e seis meses. Do mesmo modo, a extinção de diversos cargos vagos dissonantes com as práticas gerenciais e das demandas administrativas - que impõem um novo modelo administrativo decorrente da globalização com a focalização do Estado nos pontos estratégicos-, impulsionando a economia nacional num cenário internacional, ao extinguir os cargos de datilografo, recepcionista, telefonista, ${ }^{1}$ entre outros na Administração Pública Federal, além da redução dos cargos em comissão e das funções de confiança. ${ }^{2}$ Igualmente, a simplificação no atendimento aos cidadãos que utilizam os serviços públicos (Decreto n ${ }^{0}$ 9.094/2017). ${ }^{3}$ E da mesma forma, o fato dos concursos públicos se tornarem praxe da realidade brasileira, não somente mera previsão constitucional.

1 O Decreto 9.262 de 2018 extinguiu inúmeros cargos vagos na Administração Pública Federal totalizando de mais de 60 mil. O Decreto pode ser acessado através do link http://www.planalto.gov.br/ccivil_03/_ato2015-2018/2018/decreto/D9262.htm (Acesso em 20 de jun. de 2019).

2 O Decreto 8.949 de 2016 reduziu 4.600 cargos em comissão e de funções de confiança na Administração Pública Federal. Acesso na íntegra está disponível através da página http://www.planalto.gov.br/ccivil_03/_ato2015-2018/2016/decreto/D8949. htm (Acesso em 20 de jun. de 2019).

3 O Decreto 9.094 de 2017 pode ser acessado através do link http://www.planalto.gov. br/ccivil_03/_Ato 2015-2018/2017/Decreto/D9094.htm (Acesso em 20 de jun. de 2019). 
Já na Venezuela, esta pode ser vista como quatro tendências que se sucedem ao longo desse tempo, segundo Brewer-Carías (2012): I) a multiplicação da Administração Ministerial sem nenhum tipo de planejamento; II) dispersão da capacidade administração; III) centralização do processo; IV) surgimento de organizações paralelas. Um dos motivos condutores decorre da nova lei orgânica da administração pública venezuelana que dará mais poderes e competências ao Presidente para legislar mediante de Decreto; ${ }^{4}$ já no Brasil, é necessário controle legislativo para as competências elencadas no caso venezuelano a seguir.

con la nueva Ley Orgánica, la organización ministerial pasó a ser competencia del Poder Ejecutivo [...] corresponde al Presidente de la República la potestad de fijar, mediante decreto, el número, denominación, competencias y organización de los ministerios y otros órganos de la Administración Pública Nacional, con base en parámetros de adaptabilidad de las estructuras administrativas a las políticas públicas que desarrolla el Poder Ejecutivo Nacional y en los principios de organización y funcionamiento establecidos en la ley orgánica (Brewer-Carías 2012: 3).

Dessa forma, a burocracia da venezuelana foi se concentrando no Poder Executivo, em detrimento da Administração Indireta, sendo esta privilegiada no caso brasileiro, como também da supressão de responsabilidades e competências para os níveis estaduais e municipais no caso da Venezuela. Como bem expõe Brewer-Carías (2012), por meio de Decreto-Lei criou-se apenas uma Administração Pública, na qual os Estados e Municípios estão submetidos ao planejamento centralizado de políticas públicas. Outrossim, eliminou-se o conceito e a própria palavra autonomia tanto no diploma legal quanto na prática administrativa.

Dessa forma, o planejamento foi inserido numa visão centralizadora sob a justificativa de ser um problema estrutural e histórico, conforme consta na exposição de motivos da Lei de Criação da Comissão Central de Planejamento (Brewer-Carías 2012; Venezuela 2008). Nesse mesmo aspecto,

4 A Constitucionalidade do Decreto-lei nº 6217 não será debatida, visto que extrapolaria o objetivo deste trabalho. 
segundo o documento oficial, a lei mitiga a autonomia dos órgãos, das entidades, além dos Estados e Municípios, sob a justificativa de serem mal exercidos, com a finalidade de criar uniformidade à ação governamental, pois essas pessoas jurídicas do direito público estão sometidas às decisões da Comissão que é exercida pelo Vice-presidente da República, vinculado ao Ministério de Planificación y Finanzas (Brewer-Carías 2012; Venezuela 2008). Portanto, é possível notar sob esse prisma que

a autoridade governamental tenta impor as modalidades como sendo o conteúdo da decisão. Depois de ter feito preparar, de modo secreto, se possível, as decisões desejáveis, estas últimas serão, por exemplo, apresentadas aos conjuntos dos atores envolvidos como sendo "para pegar ou largar" (Muller e Surel 2002: 107).

Diante do exposto, uma vez posta a reforma administrativa na América Latina, o Estado Nacional possui função determinante tanto para o sucesso como para o fracasso desta. Logo, a capacidade estatal se sobressai como eixo fundamental entre a reforma administrativa, o êxito e a continuação nos anos posteriores, visto que

no caso da América Latina, Silberman reconhece a importância do regime de governo para a configuração da burocracia, fator desconsiderado nos seus estudos de caso. Quer dizer, a seu ver o regime de governo não foi determinante para o sucesso das reformas nos países desenvolvidos, mas o é para inviabilizá-la nos países em desenvolvimento (Cruz 2009: 21).

Para tanto, a parte seguinte será dedicada a explicar como a capacidade estatal de ambos os países se desenvolveram ao longo dos anos, além de expor quais setores foram considerados prioritários e os possíveis êxitos e fracassos.

\section{A CAPACIDADE ESTATAL}

Conforme discorrido anteriormente, a reforma administrativa pode ter a função de impulsionar ou, caso malograda, enfraquecer o Estado nacional. Assim, as reformas administrativas empreendidas pelo Brasil e pela 
Venezuela repercutem diretamente num tema essencial para a eficácia e efetividade da política pública: a capacidade estatal.

De acordo com Souza (2016), a capacidade estatal é mensurada através das políticas públicas que traduzem efetividade para a população por meio da atuação dos atores nacionais. Nesse sentido, a autora aborda dois processos que são conditio sine qua non para analisar a capacidade burocrática: (I) o processo de burocratização; (II) a capacidade burocrática do governo nacional.

Dessa forma, segundo Souza (2016), deve-se destacar para a referida análise no processo de burocratização do Estado, os seguintes aspectos: profissionalização e qualidade do processo correlacionando, na medida do possível, a qualificação profissional, mas sobretudo as formas de recrutamento e outras formas de promoção; assim como accountability, o caráter vinculativo da capacidade estatal e como esta se relaciona com a cidadania; e o objeto de promoção da reforma administrativa.

No processo de recrutamento, faz-se necessário algumas observações. De acordo com a Constituição Federal de 88, a administração pública será regida dentre outros pelos seguintes princípios:

Art. 37. A administração pública direta e indireta de qualquer dos Poderes da União, dos Estados, do Distrito Federal e dos Municípios obedecerá aos princípios de legalidade, impessoalidade, moralidade, publicidade e eficiência e, também [...] (grifo nosso).

Vale lembrar que a impessoalidade é condição essencial para a eficiência e eficácia da burocracia, pois considera-se as pessoas como ocupantes de cargos e funções impessoais, e não como do exercício da própria pessoa (Weber 2015). Esta foi a primeira reforma administrativa do Estado moderno, segundo Bresser Pereira (2017).

Como então garantir que o princípio da impessoalidade? Como o art. 37 supra se torna efetivo para a participação cidadã no Estado e para o acesso aos cargos públicos? Uma dessas respostas advém das garantias constitucionais, conforme o inciso II, do referido artigo na Constituição Federal de 88, desde que a prática da administração pública ao longo dos 
anos esteja associada com a norma fundamental, constituindo a institucionalidade e rule of law.

Pese que a previsão do legislador de exceção à regra do concurso, os cargos em comissão, estes não estão contidos na discricionariedade in totum do administrador público. Isso decorre de princípios constitucionais implícitos como a razoabilidade e proporcionalidade, como bem assentou a Suprema Corte na Tese 1010. Ressalta-se que estes cargos são apenas para chefia, assessoramento e direção, conforme previsão constitucional, art. $37, \mathrm{~V}$.

Na mesma linha desse processo, é necessário verificar a qualidade do processo e da burocracia, segundo Souza (2016). Na reforma administrativa, desencadeada pelo então Presidente Fernando Henrique (1995-2002), foi constitucionalizado o princípio da eficiência (art. 37). Ademais, a possibilidade de o servidor estável perder o cargo em virtude avaliação periódica (art. 41, II), por baixo desempenho, na forma da lei complementar, como também por excesso de despesa com pessoal (art. 169).

Resguarda-se também a vedação de contrato temporário por tempo indeterminado, a manutenção do regime jurídico único dos servidores públicos efetivos da administração pública indireta e direta, embora tenha havido uma tentativa de flexibilização e que foi vigente até o julgamento da ADI 2.135 em 2007, o qual afastou o sistema híbrido em virtude de não cumprimento do processo legislativo adequado para esta Emenda à Constituição. Salienta-se que as empresas públicas e de sociedade de economia mista são vistas mais do ponto gerencial, por também fazerem parte da administração pública indireta.

É certo que esses mecanismos são decorrentes de uma política pública advinda desde a fundação do Departamento Administrativo do Serviço Público (DASP) em 1938, como forma de profissionalização e organização do serviço público, a fim diminuir a patronagem e aumentar a racionalidade do processo administrativo. Igualmente, durante o período militar por meio do Decreto-Lei 200/1967. Logo

a principal agenda no Brasil foi construção de instituições democráticas nas quais o acesso ao serviço público pela via do concurso se inseriu como 
forma de romper com a patronagem e fazer cumprir os requisitos de uma democracia avançada, bandeiras que foram consagradas na Constituição de 1988 (CF/1988) (Souza 2016: 61).

Desse modo, o Brasil diferenciou-se do vizinho latino embora com percalços. Na Venezuela, embora haja previsão de constitucionalização do concurso público como no Brasil, esta não se demonstrou efetiva ao longo dos anos após sua promulgação, dada a baixa eficácia do concurso público (art. 146 da Constituição de 99) que ficou, muitas vezes, restrito aos cargos de professor. ${ }^{5}$ Da mesma forma, aqueles que se apresentaram positivados constitucionalmente, não obtiveram a devida eficácia, visto que foram pouquíssimas vezes aplicáveis, e logo abandonados, em especial, em relação ao da Magistratura, conforme demonstra Canova e Herrera:

En este periodo, hubo un importante proceso de depuración que se desvirtuó cuando la Comisión Judicial decidió, en el año 2003, suspender los concursos públicos de oposición para el ingreso a la judicatura, que se habían iniciado en el 2000, de manera lenta pero conforme la nueva Constitución (Canova e Herrera 2014: 22).

O caso venezuelano é peculiar, isso porque segundo a norma constitucional, artigo 255 e 291, respectivamente, preveem que:

El ingreso a la carrera judicial y el ascenso de los jueces o juezas se hará por concursos de oposición públicos que aseguren la idoneidad y excelencia de los o las participantes y serán seleccionados por los jurados de los circuitos judiciales, en la forma y condiciones que establezca la ley (grifo nosso).

Su organización y funcionamiento lo determinará la ley respectiva y estará bajo la dirección y responsabilidad del Contralor General de la Fuerza Armada quien será designado mediante concurso de oposición (art. 291) (grifo nosso).

5 Pese a existência de ocorrência alguns de concursos públicos para cargos como analistas, técnicos em alguns órgãos e algumas entidades públicas na Venezuela, a seleção nada se assemelha ao modelo brasileiro, que garante a impessoalidade na seleção, visto que os candidatos são avaliados, via de regra, pela "experiência profissional" no caso venezuelano. 
Disso resultará que a burocracia venezuelana apontará nível elevado de servidores temporários, demissíveis ad nutum, inclusive magistrados, como salienta Canova e Herrera (2014) e Gazdik (2011), motivo pelo qual acarretará de igual modo menor capacidade burocrática estatal seguindo a linha teórica de Souza (2016). Inclui-se também a decaimento da vitaliciedade e maior dependência dos magistrados ao Poder Executivo, o que não se verifica no caso brasileiro. No mesmo sentido, o aumento exacerbado de juízes provisórios, os quais compõem até $80 \%$ de todo o Poder Judiciário venezuelano, conforme relatório da Human Rights Watch (2008).

Nesse interstício, enquanto no Brasil o número de servidores público aumentou em $60 \%,{ }^{6}$ no país vizinho este incremento se dará se forma drástica e sem qualquer planejamento estrutural, tampouco resguardando a máquina pública do clientelismo, conforme é demonstrado na tabela a seguir. Recorda-se que boa parte desse aumento também decorre do aumento descomunal das Forças Armadas da Venezuela (Petkoff 2010).

Tabela 1. Variação da força laboral por setor empregador

\begin{tabular}{|l|c|c|c|}
\hline & $\begin{array}{c}\text { Var.percentual } \\
1989-1999\end{array}$ & $\begin{array}{c}\text { Var.percentual } \\
1999-2009\end{array}$ & $\begin{array}{c}\text { Var. percentual } \\
1999-2014\end{array}$ \\
\hline Setor público & $14,50 \%$ & $69,16 \%$ & $99,50 \%$ \\
\hline Setor privado formal & $16,10 \%$ & $51,93 \%$ & $71,33 \%$ \\
\hline Setor privado informal & $88,00 \%$ & $15,77 \%$ & $19,09 \%$ \\
\hline Total & $43,90 \%$ & $36,15 \%$ & $49,04 \%$ \\
\hline
\end{tabular}

Fonte: INE, ODH Grupo Consultor apud Abadi e García 2016.

Desse modo, a prática governamental, a good governance associadas aos comandados constitucionais, assim como a efetividade, legitimação,

6 METROPÓLES. Total de servidores públicos aumenta 60\% no país em 20 anos: Estudo divulgado pelo Instituto de Pesquisa Econômica Aplicada (Ipea) aponta que maior parte do aumento ocorreu nos municípios. Disponível https://www.metropoles. com/brasil/servidor-brasil/total-de-servidores-publicos-aumenta-60-no-pais-em-20-anos (Acesso em 10 de jun. de 2019). 
accountability dos processos dos mesmos e o direcionamento para a esfera pública servirá para explicar o porquê de a capacidade brasileira ser maior e mais efetiva do que a do vizinho latino. Como bem elenca Souza (2016), a burocracia ao carecer de regras e procedimentos uniformes, além da ausência de amplitude de acesso aos cargos públicos, tampouco a democratização dos cargos, infirma as perspectivas de capacidade de estatal.

É peculiar certamente como essas burocracias tanto a brasileira quanto a venezuelana encaram os referidos problemas, pois há de ambos os lados um comando imperativo que fundamenta a participação democrática nos cargos públicos da administração pública, se por um lado é efetiva, por outro há pouca aplicabilidade - este no caso da Venezuela. Daí a conexão entre a capacidade da reforma administrativa, estatal e a respectiva implementação, pois, como elenca Souza (2016), nos órgãos nos quais há mais servidores comissionados há baixa efetividade do referido Ministério na participação de políticas pública e sua respectiva qualidade, assim como da imperatividade do ocupante em seguir os comandos dos superiores, ainda que não estejam de acordo com os diplomas legais, o que muitas vezes o torna refém da vontade política.

$\mathrm{Na}$ Venezuela criou-se a militarização do poder, visto que será no período constitucional de Chávez que se aumentará e priorizará não somente os vencimentos dos militares, mas também o próprio efetivo militar, incluindo a participação na política (antes da Constituição de 99, era vedado ao militar o direito ao voto) (Petkoff 2010). Essa priorização do setor militar, decorrente de uma suposta invasão imperialista, como costumava dizer Hugo Chávez, afetará fundamentalmente a capacidade de desenvolvimento de políticas públicas, e transbordará na centralização administrativa.

Diferentemente ocorreu no Brasil. Na reforma administrativa durante a década de 90 que visava, a priori, modernizar a própria burocracia, a fim de garantir regras, procedimentos sem que o objetivo principal fosse a redução mínima do Estado, ainda que houvesse indiretamente e pontualmente alguma redução, associava-se e orientava-se para a cidadão, conforme debatido por Souza (2016) e Bresser Pereira (1998). 
Desse modo, vai ao encontro da abordagem de Souza (2016) e Bresser Pereira (1998) que asseveram que converter em norma constitucional a previsão de concurso público foi um dos acertos do legislador no processo da Constituinte de 88. Isso ocorre porque em países subdesenvolvidos, como também em desenvolvimento, geralmente, reina-se a patronagem, a qual é combatida durante anos no Brasil, mas densamente vivenciada ainda na Venezuela. Afinal, como bem elenca Borner "é a debilidade institucional que impede na América Latina, que se extraia todo o proveito potencial dos generosos recursos naturais e humanos que se concentram na região" (I Catalá 2006: 279).

Outrossim, é através do princípio da moralidade que o STF aprovará há mais de anos 10 anos, em 2008, a Súmula Vinculante 13 que veda a prática de nepotismo nos três poderes em todos os graus do federalismo brasileiro: Federal, Estadual e Municipal. Desse modo, pese a promulgação da CF tenha ocorrido em 1988, foi num lapso de 20 anos que a Suprema Corte se retira da inércia jurisdicional. Por outro lado, não há decisão referente ao tema, ainda que se tenha incrementado o nepotismo no país durante o período Chávez, como destaca Aguiar (2012).

Por isso, as práticas que foram proibidas no Brasil, ainda são pertinentes Venezuela, reluz-se por não haver efetivo meio de acesso impessoal para a seleção aos cargos públicos, por exemplo. De todos os modos, é possível afirmar que a institucionalidade associado as supracitadas garantias constitucionais impulsionam e fortalecem a democracia, mas também a capacidade burocrática do país, havendo uma correlação entre esses fatores, da mesma forma na qualidade de prestação ao cidadão - a eficiência, eficácia e efetividade -, tendo em vista que seu destinatário sempre é, e assim deve ser, o bem comum e a cidadania.

\section{CONSIDERAÇÕES FINAIS}

Diante do exposto pode-se concluir que a administração pública, assim como a reforma administrativa no Brasil e na Venezuela caminharam diversamente nos períodos elencados. É fundamental elencar que a profis- 
sionalização da administração pública no Brasil avançou mais do que na Venezuela. Já no segundo momento, havia democratização na Venezuela, enquanto no Brasil boa parte remanesceu sob o domínio dos militares, os quais não possuíram a preocupação de atender as demandas sociais, a priori, nem dividir essencialmente o poder com partidos que sequer poderiam ameaçá-los no poder.

No entanto, esse período é rompido e ambas se assemelham durante a década 90 até 1999, pois além de estarem num período democrático, são vivenciadas práticas análogas para a implementação de uma reforma administrativa que esteja mais conexa e mais sensível à demanda popular ao mesmo tempo consoantes as diretrizes das organizações internacionais, como FMI, Banco Mundial.

Nesse sentido, a capacidade estatal para implementação da reforma é fundamental. $\mathrm{E}$ isso repercute nos governos posteriores: a reforma administrativa, accountability, a institucionalidade, maiores formas de controle popular, adoção de medidas que protegem o patrimônio público são continuadas e revigoradas nos períodos Lula, Dilma e Temer, o que pode explicar a maior capacidade estatal de implementação de políticas públicas do que a Venezuela.

Por outro lado, a descontinuidade, mas também, a regressão por parte da Venezuela ao passar à centralização dos processos administrativos e da formulação das políticas públicas, reduzindo o federalismo, o que já mitiga a eficácia, eficiência e efetividade das políticas públicas, visto o lapso espacial entre o poder nacional e o cidadão, demonstra um dos pontos que diferencia as etapas e os resultados dos países e, portanto, podem explicar como e o porquê da administração pública brasileira e venezuelana estarem tão distante atualmente.

Por fim, torna-se essencial reafirmar a capacidade do Estado em promover as devidas reformas, como também de manté-las, aperfeiçoá-las em consonância com a realidade local. Outrossim, a descentralização se tornou um instrumento mister para maior eficácia e efetividade das políticas públicas, o qual não pode ser negligenciado, senão promovido pelos poderes públicos: para que o Estado seja positivo ao cidadão. 


\section{REFERÊNCIAS BIBLIOGRÁFICAS}

ABadi, ANabella y Carlos García. "¿Cómo ha crecido el Poder Ejecutivo en Venezuela entre 1998-2015". Disponível http://historico.prodavinci. com/blogs/como-ha-crecido-el-poder-ejecutivo-en-venezuela-entre-1998-2015-por-anabella-abadi-y-carlos-garcia/ (acesso em 10 de jun. de 2019).

ABRUCiO, FERNANDO Luiz. "Os avanços e os dilemas do modelo pós-burocrático: a reforma da administração pública à luz da experiência internacional recente". Luiz Carlos Bresser Pereira y Peter Spink (orgs.). Reforma do Estado e administração pública gerencial. Rio de Janeiro: Editora FGV, 2006.

ADDO, FeliPE. "Passos para construção de uma nova democracia no contexto venezuelano". Karl Schurster y Rafael Araujo (orgs.). A era Chávez e a Venezuela no tempo presente. Rio de Janeiro: Autografia, Edupe, 2015.

Aguiar, ASDRúBAL. Historia inconstitucional de Venezuela (1999-2012). Caracas: Editorial Jurídica Venezolana, 2012.

BRASIL. Constituição Federal de 1988. Promulgada em 5 de outubro de 1988. Disponível http://www.planalto.gov.br/ccivil_03/constituicao/ constitui cao.htm (acesso em 10 de jun. de 2019).

BRASIL. Decreto-lei no 200/1967. Promulgada em 5 de outubro de 1988. Disponível http://www.planalto.gov.br/ccivil_03/Decreto-lei/del0200.htm (acesso em 22 de jun. de 2019).

Bresser Pereira, Luiz Carlos. Reforma do Estado para a cidadania: a reforma gerencial brasileira na perspectiva internacional. Brasília: ENAP, 1998.

BResser Pereira, Luiz Carlos. "Gestão do setor público: estratégia e estrutura para um novo Estado". Luiz Carlos Bresser Pereira y Peter Spink (orgs.). Reforma do Estado e administração pública gerencial. Rio de Janeiro: Editora FGV, 2006a.

BResser Pereira, Luiz Carlos. "Da administração pública burocrática à gerencial”. Luiz Carlos Bresser Pereira y Peter Spink (orgs.). Reforma do 
Estado e administração pública gerencial. Rio de Janeiro: Editora FGV, 2006b.

BresSer Pereira, Luiz Carlos. "Reforma gerencial e legitimação do estado social". Disponível http://www.scielo.br/scielo.php?script=sci_arttext\&pid $=$ S0034-76122017000100147\& lng $=$ pt\&nrm $=$ isso (acesso em 23 jun. 2019).

BREWER-CARÍAS, AlLAN R. "La experiencia de reforma administrativa en Venezuela 1969-1973. Estrategias, tácticas y criterios". Reforma Administrativa: Experiencias Latinoamericanas. México: UNAM, 1975. 193-234.

BREWER-CARÍAS, ALLAN R. Estudios sobre la reforma administrativa. Caracas: Ediciones de la Biblioteca de la Universidad Central de Venezuela, 1980.

BreWER-Carías, Allan R. "¿Reforma administrativa en Venezuela? O la transformación no siempre planificada de la administración pública, para la implementación de un Estado Socialista al margen de la Constitución, mediante la multiplicación, dispersión y centralización de sus órganos y entes". Cuarto Congreso Iberoamericano y Quinto mexicano de Derecho Administrativo. Xalapa: Instituto de Investigaciones Jurídicas, 2012.

CANOVA GONZÁLEZ, ANTONIO y LUIS ALFONSO HERRERA. El TSJ al servicio de la Revolución: la toma, los números y los criterios del TSJ venezolano (2004-2013). Caracas: Galipán, 2014.

Canova González, Antonio y luis Alfonso Herrera. "Introducción". Antonio Canova González y Luis Alfonso Herrera (orgs.). El TSJ al servicio de la Revolución: la toma, los números y los criterios del TSJ venezolano (2004-2013). Caracas: Galipán, 2014.

Chiavenato, IDAlBerTo. Teoria Geral da Administração: abordagens descritivas e explicativas. Vol. II. Barueri: Manole, 2014.

Chudnovsky, Mariana. "Introducción: Por qué capacidades estatales y esta selección para comprenderlas”. Mariana Chudnovsky (orgs.). Capacidades estatales: diez textos fundamentales. Buenos Aires: Corporación Andina de Fomento, 2015. 
Coppedge, Michael. Strong Parties and Lame Ducks: Presidential Partyarchy and Factionalism in Venezuela. Stanford: Stanford University Press, 1994.

Coppedge, Michael. Soberanía popular versus democracia liberal en Venezuela. Marisa Ramos (ed.). Venezuela: rupturas y continuidades del sistema político (1999-2001). Salamanca: Ediciones Universidad de Salamanca, 2002.

CóRdova Jaimes, Edgar. "Administración Pública en Venezuela: Aproximaciones a los cambios y transformaciones". Revista de Ciencias Sociales 12.3 (2006): 496-518.

Corrales, Javier y Michael Penfold. Un dragón el trópico. Caracas: La Hoja del Norte, 2012.

CRuZ, RaQuel PelLizZoni. A Formação das Carreiras Burocráticas segundo Bernard Silberman. Disponível http://www.fonacate.org.br/v2/?go $=$ downloads\&id $=10$ (acesso em 20 jun. de 2019).

FuRTADO, CELSO. Ensaios sobre a Venezuela: subdesenvolvimento com abundância de divisas. Rio de Janeiro: Contraponto, 2008.

GAZDIK, RAFAEL J. ChavERO. La justicia revolucionaria: una década de reestructuración (o involución) judicial en Venezuela. Caracas: Editorial Aequitas, 2011.

Human Rights Watch. A Decade Under Chávez: Political Intolerance and Lost Opportunities for Advancing Human Rights in Venezuela. Nova Iorque: Human Rights Watch, 2008.

I CATALÁ, JOAN PRATS. "Governabilidade democrática na América Latina no final do século XX”. Luiz Carlos Bresser Pereira y Peter Spink (orgs.). Reforma do Estado e administração pública gerencial. Rio de Janeiro: Editora FGV, 2006.

LÓPEZ MAYA, MARGARITA. Del viernes negro al referendo revocatorio. Caracas: Alfa, 2016a.

LÓPEZ MAYA, MARGARITA. El ocaso del chavismo. Caracas: Alfa, 2016b.

Magdaleno, John. "La historia de un desencanto: el fin de la 'democracia pactada' y el ascenso de la 'revolución chavista' en Venezuela". 
Congreso Latinoamericano de Ciencia Política. Quito: Asociación Latinoamericana de Ciencia Política, 2012: 1-26.

Millán, Jorge A. Sistema Político Venezolano: Transición Inacabada. Scotts Valley: Create Space Independent Publishing Platform, 2016.

MudDE, CAs. Populismo. Uma brevíssima Introdução. Lisboa: Gradiva, 2017.

Muller, PIERRE. Las políticas públicas. Bogotá: Universidad Externado de Colombia, 2002.

Muller, Pierre e Yves Surel. A Análise das políticas públicas. Pelotas: Educat, 2002.

NAím, MoIsÉs. "The Real Story Behind Venezuela's Woes". Journal of Democracy 12.2 (2001): 17-31.

Petkoff, Teodoro. El chavismo como problema. Caracas: Libros Marcados, 2010.

PRZEWORSKI, ADAM. "Sobre o desenho do Estado: uma perspectiva agente $x$ principal". Luiz Carlos Bresser Pereira y Peter Spink (orgs.). Reforma do Estado e administração pública gerencial. Rio de Janeiro: Editora FGV, 2006.

REY, JUAN CARLOS. El futuro de la democracia en Venezuela. Caracas: IDEA, 1989.

RIVAS LEONE, José ANTONIO. Los desencuentros de la política venezolana: nacimiento, consolidación y desinstitucionalización de los partidos políticos, 1958-2007. Caracas: Fundación para la Cultura Urbana, 2008.

SOUSA SANTOS, BOAVENTURA e LEONARDO AVRITZER. "Introdução: para ampliação o cânone democrático". Boaventura de Sousa Santos (orgs.). Democratizar a Democracia: Os caminhos da democracia participativa. Rio de Janeiro: Civilização Brasileira, 2002.

SouzA, Celina. "Capacidade Burocrática no Brasil e na Argentina: quando a política faz a diferença". Alexandre de Ávila Gomide y Renato Raul Boschi. Capacidades estatais em países emergentes: o Brasil em perspectiva comparada. Rio de Janeiro: Ipea, 2016. 
SouzA, Celina. "Políticas públicas: uma revisão da literatura". Sociologias 8.16 (2006): 20-45.

STAMBOULI, ANDRÉS. La política extraviada: una historia de Medina a

Chávez. Caracas: Fundación para la Cultura Urbana, 2005.

Urbaneja, Diego Bautista. La política venezolana desde 1958 hasta

nuestros días. Caracas: Universidad Católica Andrés Bello, 2009.

VENEZuela. Constitución de la República Bolivariana de Venezuela.

Disponível em https://www.oas.org/juridico/mla/sp/ven/sp_ven-int-const.html (acesso em 10 de jun. de 2019).

Venezuela. Exposición de motivos. Disponível em http://extwprlegs1.fao. org/ docs/ pdf/ven97786.pdf (acesso em 10 de jun. de 2019).

Vilda De Juan, Carmelo. Proceso de la cultura em Venezuela. Caracas: Universidad Católica Andrés Bello, 1999.

WAhrlich, Beatriz Marques DE SOUSA. "Reforma administrativa federal brasileira: passado e presente". Revista de Administração Pública 8. 2 (1974): 27-76.

WeBER, MAX. Economia e Sociedade: fundamentos da sociologia compreensiva, volume 1. Brasília: Editora da Universidade de Brasília, 2015. 